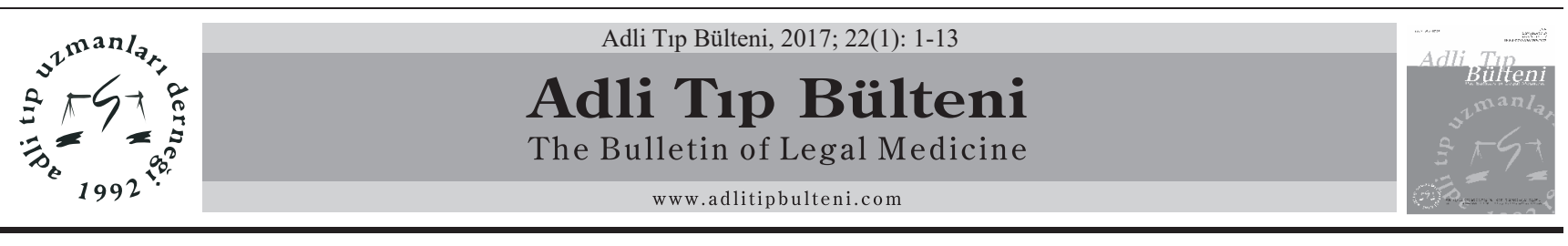

\title{
EI Yazısı İncelemelerinde Kullanılan Bireysel Karakteristiklerin Kanıt Değerinin Veri Tabanındaki Frekanslara Göre Belirlenmesi
}

\section{Determination of Evidence Evaluation of Individual Characteristics Used in Handwriting Analysis According to the Frequencies in Database}

\author{
Dilara Öner ${ }^{1}$, Salih Cengiz ${ }^{1}$, Gürsel Çetin ${ }^{2}$

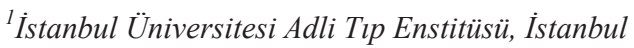 \\ ${ }^{2}$ Istanbul Üniversitesi Cerrahpaşa Tıp Fakültesi Adli Tip Anabilim Dall, Ístanbul
}

\begin{abstract}
Özet
Amaç: Bu çalışmada veri tabanı oluşturulması sureti ile yazı incelemeleri ve karşılaştırmalarında elde edilen sonuçların güvenilirliğinin olasılık oranları yolu ile matematiksel olarak belirlenebilmesi amaçlanmıştır.

Gereç ve Yöntem: Amaç doğrultusunda üniversite veya lisansüstü eğitim programlarından mezun olmuş veya halen öğrenim görmekte olan 500 kişiye tek tek harfler, rakamlar ve özel olarak hazırlanmış tüm harfleri, rakamları büyük ölçüde bağlantı ve noktalamaları içeren bir metin ikişer kez yazdırılmıştır. Yazdırılan örnekler yüksek çözünürlükte taranarak bilgisayar ortamına aktarılmıştır.

Farklı kişilere suç teşkil edecek nitelikteki bir cümle kaçma gayreti içerisinde ancak bazı harfler değiştirilmeden yazdırılarak bu alanda çalışan ve bu yayında yazar olmayan üç uzmandan inceleme konusu cümleleri karşılaştırma olarak alınan örneklerle kıyaslamaları ve aidiyet gösterecek özellikleri saptamaları istenmiştir.

Bulgular: Uzmanlar tarafından tespit edilen harflerin yapılışına ve formuna ait benzerlikler veri tabanında araştırılmış ve aidiyetin belirlenmesinde rol oynayan bu benzerliklerin veri tabanındaki dolayısıyla toplumdaki görülme sıklıkları belirlenerek varılan sonuçların matematiksel olarak güvenilirliği ortaya konmuştur.

Sonuç: Son yıllarda konu ile ilgili çok sayıda bilimsel çalışmanın 1şığı altında yapılan bu çalışmada benzerlik olarak saptanan bazı özelliklerin veri tabanında yüksek oranda görülebildiği buna karşılık bazı özelliklerin çok nadir görüldüğ̈ saptanmıştır. Bu nedenle alanda çalışan bir uzmanın ya genel olarak oluşturulmuş veri tabanlarını kullanması veya yıllar içerisinde kendisinin arşivlediği örnekleri veri tabanı haline getirmesinin çok büyük önem taşıdığı sonucuna varılmıştır.

Anahtar Kelimeler: Belge İnceleme; Yazı Karşılaştırmaları; Veri Tabanı; Olabilirlik Oranı; Kanıt Değeri.
\end{abstract}

\begin{abstract}
Objective: The aim of the study is to determine the reliability of the results gained from the hand-writing investigations and comparisons mathematically by using likelihood ratios in order to form a database.

Materials and Methods: For this purpose, 500 people graduated from university or post-graduate institutions or still studying, were used to write the letters and numbers one by one and a special text containing all the letters and numbers with punctuation and connections, twice. All the written samples were scanned with high resolution and transferred to a computer.

A sentence which has a criminal offense were written in an effort to escape without changing some of the letters by different individuals. Three experts who are not authored in this publication were offered to compare the sentences with the collected samples and to determine the characteristics that will show belonging.

Results: The similarities for the construction and forms of the letters that were determined by the experts were searched in database, and the frequencies of these similarities in databases and society were determined to elucidate the mathematical reliability of the results obtained from the study.

Conclusion: In recent years, there are lots of scientific studies related with this topic and this study was performed under the light of these studies. Some characteristics determined as similarity were highly seen in the Database whereas some characteristics were rarely seen. As a result, it was concluded for an expert it has a great importance that he or she should use either a general database or create a database from the archived samples.
\end{abstract}

Keywords: Document Examination; Handwriting Comparisons; Database; Likelihood Ratio; Evidence Evaluation.

maları, intihar notlarında olduğu gibi kriminal olayların çözümünde büyük rol oynamaları sebebiyle önem taşımaktadır.

Çok sayıda olayda yazı ve imzanın belli bir kişiye ait olup olmadığı, farklı yazı ve imzaların aynı kişiye ait olup olmadığı veya bir metinde kaç farklı kişiye ait yazı bulunduğu konusunda tespit yapılması hukuksal açıdan çok büyük önem taşımaktadır. Bu konuda direkt olarak belli bir yazı veya imzanın kime ait olduğunun belirlenmesinde kullanılabilecek teknik bir yöntem henüz mevcut değil-

Sorumlu Yazar: Dilara Öner

İstanbul Üniversitesi Adli Tip Enstitüsü, İstanbul

E-mail: dilara.oner24@gmail.com

Geliş:11.11.2016 Düzeltme:09.02.2017 Kabul:28.02.2017 
dir. Kullanılan yöntem; incelenen yazı veya imzanın belli kişi veya kişilere ait olduğu bilinen yazı ve imzalar ile karşılaştırılması esasına dayanmaktadır. Elbette ki bu karşılaştırmada yardımcı teknolojik imkânların kullanılması mümkündür. Ancak esas olan, göz ile yapılan karşılaştırma ve varılan kanaattir. Dolayısıyla yapılan değerlendirme sonuçlarının uzmandan uzmana değişiklik göstermesi ve subjektivite yüzdesinin yüksek olması beklenebilir. İki şeklin farklı özellikler bakımından değerlendirilirken ve aralarındaki benzerlikler ve/veya farklılıklar saptanırken görüş ayrılıklarının ortaya çıkması doğaldır.

Son yıllarda adli bilimlerin diğer alanlarında olduğu gibi yazı ve imza incelemelerinde de tespit edilen sonuçların güvenilirliğini arttırmak ve bu güvenilirliği matematiksel olarak ölçülebilir hale getirmek amacı ile önemli çalışmalar yapılmaktadır (1-37). Bu çalışmalardaki temel nokta özellikle yazı örnekleri bakımından bir veri tabanı oluşturmak ve bu veri tabanına göre yazıların incelenmesinde ve karşılaştırılmasında saptanan ve bireysel karakteristik olarak kabul edilen bulguların toplumda hangi sıklıkta görüldüğünün tespit edilmesidir. Yazı karşılaştırmalarında özellikle aidiyet belirlenmesinde rol oynayan benzerliklerin toplumda çok az görülmesi halinde matematiksel olarak tanı değeri yükselecek aksine benzerlik olarak saptanan özelliğin toplumda sık görülmesi halinde matematiksel olarak tanı değeri azalacaktır.

$\mathrm{Bu}$ çalışmanın amacı belge incelemelerinde yazı karşılaştırması yapılırken aidiyet bakımından varılan sonuçların matematiksel olarak güvenilirliğinin saptanmasında kullanılabilecek bir veri tabanı oluşturmaktır. Konu ile ilgili olarak incelenen literatürden birçok ülkede aynı amaçla veri tabanlarının oluşturulduğu anlaşılmıştır $(4,7$, 11, 38-44). Oysa ülkemizde böyle bir veri tabanı bulunmamaktadır. Diğer ülkelerde yapılan çalışmalarda olduğu gibi ülkemizde yapılan yazı incelemeleri ile ilgili bilirkişilik uygulamalarında da bu veri tabanının önemli ölçüde katkısının olacağı ve varılan sonuçların objektivitesini ve güvenilirliğini arttıracağı öngörülmektedir.

\section{Gereç ve Yöntem}

$\mathrm{Bu}$ çalışmada yazı ve rakamlara ait veri tabanı oluşturmak amacı ile üniversite mezunu veya üniversite öğrencilerinden oluşan toplam 500 kişiye hazırlanmış formlar verilerek yazı ve rakam örnekleri alınmıştır.

Yazı ve rakam örnekleri alınırken üstte bulunan bir metni alttaki boşluğa yazmaları, yine tablo şeklinde oluşturulan kutucuklara büyük ve küçük harfler ile rakamları oturur pozisyonda yazmaları istenmiştir.

Yazılması istenen metin, karşılaştırma örneği almak için özel olarak hazırlanmış ve tüm büyük-küçük harfleri ve rakamları içeren bir metindir $(45,46)$. Her kişiden ay- dınlatılmış onam formu ile birlikte söz konusu metin ve harfleri ikişer kez yazması istenmiştir. Dört adet form ile birlikte her kişiye bir boş kâğıt verilmiş formların üst üste konmaması her form doldurulurken sert zeminde altına sadece boş kâğıdın konması sağlanmıştır. Çalışmada A4 boyutunda aynı cins fotokopi kağıtları kullanılmış, her kişiye yazıları yazmada kullanacağı aynı cins mavi renkli tükenmez kalem verilmiştir.

Elde edilen formlar Canon CanoScan LIDE 220 model tarayıcıda 600dpi çözünürlükte taranarak bilgisayar ortamına aktarılmıştır.

Yazı karşılaştırmalarında veri tabanı kullanımının önem ve gerekliliğini tartışabilmek amacı ile suç teşkil edebilecek nitelikte cümleler farklı kişilere yazdırılmış ve bu cümleyi yazarken mümkün olduğunca kendi yazılarını değiştirmeleri ancak bazı harfleri kendi yazılarında olduğu gibi yazmaları istenmiştir. Aynı kişilerden oturur pozisyonda aynı cümleyi kendi yazıları ile hızlıca yazmaları istenerek iki adet karşılaştırma cümlesi elde edilmiştir.

Alınan örnek yazılar, yazı ve imza incelemeleri konusunda bilirkişilik yapan ve İl Adli Yargı Adalet Komisyonu Başkanlığı Bilirkişi Listesi'ne kayıtlı, öğretim üyesi düzeyinde üç farklı uzmana inceletilmiş ve inceleme konusu cümle ile karşılaştırmalar arasında aidiyetin tespitinde önem taşıyacak derecede formal benzerlik gösteren harfleri saptamaları istenmiştir.

Her üç uzman tarafindan ortak olarak tespit edilen ve aralarında benzerlik saptanan harfler veri tabanında araştırılarak bilgisayar ortamında kesilmiştir. Metinden kesim yapılırken her harf için beş yüz adet formda da aynı kelime kullanılmıştır. Yapılan ön değerlendirmede kutucuklara yazdırılan karakterler ile metin içinde kullanılan aynı karakterlerin önemli derecede farklılık gösterdiği dikkati çekmiş olup karakterler kutucuklardan alınmamıştır.

Kesilen her bir harf çeşidi için yapılış biçimi bak1mından gruplandırma yapılmıştır. Gruplandırma yapılırken grup sayısı bakımından herhangi bir sayı ile bağlı olmaksızın, grup sayısı o harf için bulunabilen farklı yapılış biçimi sayısı kadar arttırılmıştır. Belli bir harf için tespit edilen farklı gruplardaki harflerin yapılış biçimi ile örnek olarak belirlenen cümlelerdeki uzmanlar tarafından benzer olduğu belirtilen harfler kıyaslanmış ve benzetilen harflerin yapılış biçimi bakımından hangi gruba dâhil olduğu belirlenmiştir.

Araştırılan inceleme konusu harflerin dahil edildiği grup ikinci kez kendi arasında incelenerek sadece yapılış biçimi bakımından değil ilk bakıştaki formasyon açısından daha ileri derecede benzerlik gösteren harfler ayrılarak son grup oluşturulmuştur. Bu ayrımda herhangi bir ölçüm kullanılmamıştır. Son elde edilen grubun sayısı inceleme konusu harfin yapılış biçiminin veri tabanındaki 
sayısı olarak kabul edilmiş, oluşturduğu frekans bulunarak aynı yapılış biçiminin veri tabanındaki dolayısı ile toplumun bir kesimindeki görülme olasıllığı saptanmıştır. Benzerlik oluşturan harflerin frekansları esas alınarak "LR(Likelihood Ratio $)=\mathrm{P}(\mathrm{E} \mid \mathrm{Hp}) / \mathrm{P}(\mathrm{E} \mid \mathrm{Hd})$ " formülü ile olabilirlik oranı hesaplanmıştır. İnceleme konusu yazıyı yazan kişi ile mukayese örneğini yazan kişi aynıdır. İnceleme konusu yazıyı yazan kişi ile mukayese örneğini yazan kişi aynı değildir). $\mathrm{P}(\mathrm{E} \mid \mathrm{H})=1$ 'dir. $(2,3)$.

\section{Bulgular}

Çalışmada on kişiye ait kurgusal olgu örnekleri kullanılmıştır. Örneklerin her birinde inceleme konusu yazı ile karşılaştırmada kullanılacak olan yazılar, yazı incelemeleri konusunda bilirkişilik yapan ve İstanbul İl Adli Yargı Adalet Komisyonu Başkanlığı Bilirkişi Listesinde kayıtlı olan 3 farklı uzmana gösterilmiş olup bu uzmanlar inceleme konusu yazı ile karşılaştırmada kullanılan yazıların aynı kişinin eli ürünü olduğu kanaatine varmıştır. Her üç uzman yazıların değiştirme gayreti ile yazılmış olduğunu ancak belirli karakterlerde önemli derecede uygunluk ve benzerlikler mevcut olduğunu belirtmiştir.

\subsection{Kurgusal Olgu}

Veri tabanında yer alan kişilerden birine, tehdit amacı ile yazısını değiştirmesini isteyerek aşağıdaki inceleme konusu cümle yazdırılmıştır.

$$
\begin{aligned}
& \text { Ahmet, artik sana dayanamiyorum. Ayagini denk } \\
& \text { al oglum! }
\end{aligned}
$$

Aynı kişiye mukayesede kullanılmak üzere inceleme konusu cümlenin aynısı olan aşağıdaki cümleler yazdırılmıştır.

$$
\begin{aligned}
& \text { Ahmeti artik sana daganamiyoum. Ayagm } \\
& \text { denk at ogtum! } \\
& \text { Ahmet, artik sana dayanamyoum. Ayagen! } \\
& \text { denk al oglum! }
\end{aligned}
$$

Yukarıdaki inceleme konusu yazı ile karşılaştırmada kullanılacak olan yazılar incelendiğinde "d" ve "lu" karakterlerinde önemli derecede uygunluk ve benzerlikler mevcut olduğu belirtilmiştir.

1. Veri tabanında "d" harfinin 11 adet grup oluşturacak şekilde ayrı formu mevcuttur. Bu farklı formlar, oluşturdukları gruba ait örnekler ve veri tabanındaki sayıları Tablo 1 verilmiştir.
2. İnceleme konusu cümlede ve benzetilen karşılaştırma cümlelerindeki "d" harfi formunun yapıllışı, örnekleri, sayısı ve frekansı Tablo 1 Grup 1'de verilmiştir.

3. Tablo 1 Grup 1'de verilen 395 kişiye ait "d" harfi formları kendi arasında ikinci kez ayrıma tabi tutularak inceleme konusu ve karşılaştırma cümlelerindeki aynı harfe en çok benzeyen örnek sayısının 39 olduğu saptanmıştır. Bu örneklerin frekansı 0.078'dir (Tablo 2).

Uzmanların ortak olarak önemli derecede benzerlik saptadığ 1 "lu" bağlantısı veri tabanında araştırılmış ve aşağıdaki sonuçlar elde edilmiştir.

1. Veri tabanında "lu" harfinin 10 adet grup oluşturacak şekilde ayrı formu mevcuttur. Bu farklı formlar, oluşturdukları gruba ait örnekler ve veri tabanındaki sayıları Tablo 3'te verilmiştir.

2. İnceleme konusu cümlede ve benzetilen karşılaştırma cümlelerindeki "lu" bağlantısı formunun yapıllışı, örnekleri, sayısı ve frekansı Tablo 3 Grup 3 'te verilmiştir.

3. Tablo 3 Grup 3'de verilen 96 kişiye ait "lu" harfi formları kendi arasında ikinci kez ayrıma tabi tutularak in-

\begin{tabular}{|c|c|c|c|c|}
\hline Grup & Yapılış & Örnekler & Sayı & Frekans \\
\hline 1 & $b^{l^{1}}$ & de drdida & 395 & 0.79 \\
\hline 2 & ${ }^{1} \mathrm{~d} / \mathrm{l}^{2}$ & $d x d o d=d o$ & 16 & 0.032 \\
\hline 3 & $\hat{r} d t^{2}$ & del dedi & 45 & 0.09 \\
\hline 4 & $c d^{l}$ & da do' do fe & 23 & 0.046 \\
\hline 5 & $\stackrel{1}{d^{k}}$ & di de da de & 11 & 0.022 \\
\hline 6 & $\left.\frac{1}{2}\right|^{2}$ & dr de da & 4 & 0.008 \\
\hline 7 & & & 1 & 0.002 \\
\hline 8 & 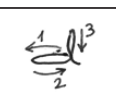 & & 1 & 0.002 \\
\hline 9 & ø๐" & of & 1 & 0.002 \\
\hline 10 & v) & 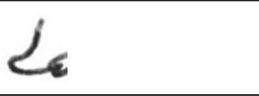 & 1 & 0.002 \\
\hline 11 & $\frac{1}{r} d^{\nu^{2}}$ & $d_{a} d c$ & 2 & 0.004 \\
\hline
\end{tabular}
celeme konusu ve karşılaştırma cümlelerindeki aynı harfe en çok benzeyen örnek sayısının 24 olduğu saptanmıştır. Bu örneklerin frekansı 0.056'dır

Tablo 1. Veri tabanında "d" harfinin oluşturduğu farklı gruplar. 
Tablo 2. Veri tabanında inceleme konusu cümledeki "d"ye en çok benzeyen örnekler.

\begin{tabular}{|c|c|c|}
\hline & Sayı & Frekans \\
\hline 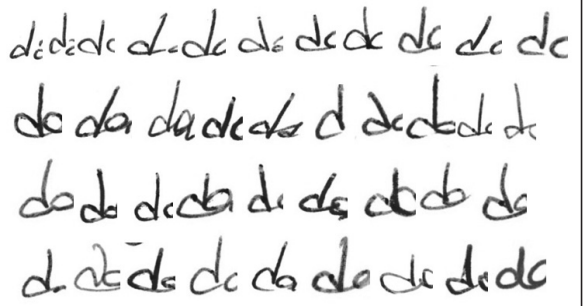 & ले & $\begin{array}{l}\infty \\
\vdots \\
0 \\
0\end{array}$ \\
\hline
\end{tabular}

Tablo 3 . Veri tabanında "lu" harfinin oluşturduğu farklı gruplar.

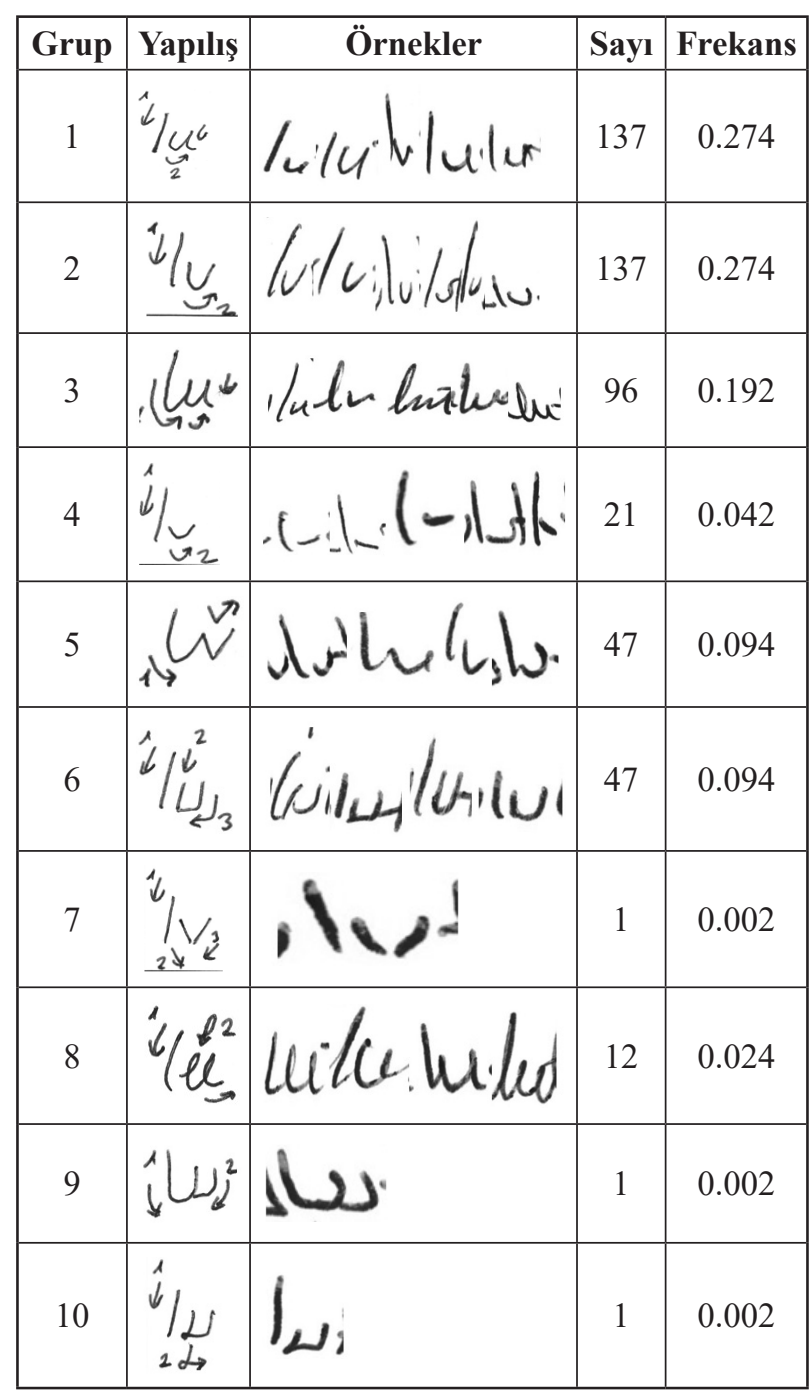

Tablo 4. Veri tabanında inceleme konusu cümledeki "lu"ya en çok benzeyen örnekler.

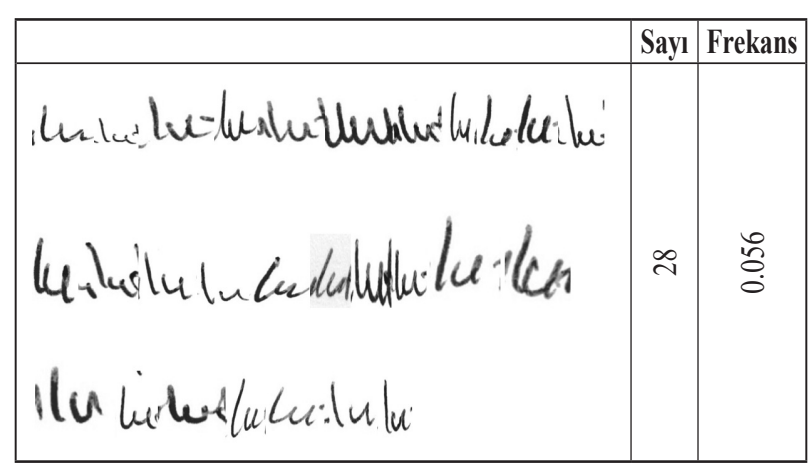

$$
\begin{gathered}
\mathrm{P}(\mathrm{E} \mid \mathrm{H})=(0,078) \times(0,056)=4.368 \times 10^{-3} \\
\mathrm{LR}=1 / 4.36 \times 10^{-3}=228.9377
\end{gathered}
$$

\subsection{Kurgusal Olgu}

Veri tabanında yer alan kişilerden birine, tehdit amacı ile yazısını değiştirmesini isteyerek aşağıdaki inceleme konusu cümle yazdırılmıştır.

\section{Güray, bir yanlis yapma}

Aynı kişiye mukayesede kullanılmak üzere inceleme konusu cümlenin aynısı olan aşağıdaki cümleler yazdırılmıştır.

$$
\begin{aligned}
& \text { Güray bir yanlis yopma } \\
& \text { Güray bir yanlis yapma }
\end{aligned}
$$

Yukarıdaki inceleme konusu yazı ile karşılaştırmada kullanılacak olan yazılar incelendiğinde "G", "b", "y" ve "ir" karakterlerinde önemli derecede uygunluk ve benzerlikler mevcut olduğunu belirtilmiştir. Uzmanların ortak olarak önemli derecede benzerlik saptadığ 1 karakterler veri tabanında araştırılmış ve aşağıdaki sonuçlar elde edilmiştir:

1. Veri tabanında "G" harfinin 19 adet grup oluşturacak şekilde ayrı formu mevcuttur.

2. İnceleme konusu yazıdaki " $G$ " harfi ile mukayesedeki "G" harfi veri tabanında 101 kişide görülmektedir ve 
bu "G" harfi formları kendi arasında ikinci kez ayrıma tabi tutulduğunda, inceleme konusu ve karşılaştırma cümlelerindeki aynı harfe en çok benzeyen örnek sayısının 56 olduğu saptanmıştır. Bu örneklerin frekansı 0.112 'dir.

3. Veri tabanında " $y$ " harfinin 11 adet grup oluşturacak şekilde ayrı formu mevcuttur.

4. İnceleme konusu yazıdaki "y" harfi ile mukayesedeki " $y$ " harfi veri tabanında 1 kişide görülmektedir ve frekans1 ise 0.002 'dir.

5. Veri tabanında "b" harfinin 9 adet grup oluşturacak şekilde ayr1 formu mevcuttur.

6. İnceleme konusu yazıdaki "b" harfi ile mukayesedeki "b" harfi veri tabanında 5 kişide görülmektedir ve frekans1 0.01 'dir.

7. Veri tabanında "ir" harfinin 17 adet grup oluşturacak şekilde ayrı formu mevcuttur.

8. İnceleme konusu yazıdaki "ir" karakteri ile mukayesedeki "ir" karakteri veri tabanında 1 kişide görülmektedir ve frekansı 0.002 'dir.

$$
\begin{aligned}
& \mathrm{P}(\mathrm{E} \mid \mathrm{Hd})=(0,078) \times(0,056)=4.368 \times 10^{-9} \\
& \mathrm{LR}=1 / 5.3453 \times 10-7=1,870,809.387
\end{aligned}
$$

\subsection{Kurgusal Olgu}

Veri tabanında yer alan kişilerden birine, tehdit amacı ile yazısını değiştirmesini isteyerek aşağıdaki inceleme konusu cümle yazdırılmıştır.

$$
\text { Babana dikkat et. Ben sakaya gelmen. }
$$

Aynı kişiye mukayesede kullanılmak üzere inceleme konusu cümlenin aynısı olan aşağıdaki cümleler yazdırılmıştır.

$$
\begin{aligned}
& \text { Pabara dikkat et. Ber saloga gelmen. } \\
& \text { Babara dikkat et. Ber sakaga gelnem. }
\end{aligned}
$$

Yukarıdaki inceleme konusu yazı ile karşılaştırmada kullanılacak olan yazılar incelendiğinde "B", "d", “y” ve " $t$ " karakterlerinde önemli derecede uygunluk ve benzerlikler mevcut olduğunu belirtilmiştir.
1. Veri tabanında "B" harfinin 15 adet grup oluşturacak şekilde ayrı formu mevcuttur.

2. İnceleme konusu yazıdaki " $B$ " harfi ile mukayesedeki " $B$ " harfi veri tabanında 273 kişide görülmektedir ve bu "B" harfi formları kendi arasında ikinci kez ayrıma tabi tutulduğunda, inceleme konusu ve karşılaştırma cümlelerindeki aynı harfe en çok benzeyen örnek sayısının 29 olduğu saptanmıştır. Bu örneklerin frekansı $0.058^{\prime}$ dir.

3. Veri tabanında "d" harfinin 11 adet grup oluşturacak şekilde ayrı formu mevcuttur.

4. İnceleme konusu yazıdaki " $d$ " harfi ile mukayesedeki "d" harfi veri tabanında 45 kişide görülmektedir ve bu "d" harfi formları kendi arasında ikinci kez ayrıma tabi tutulduğunda, inceleme konusu ve karşılaştırma cümlelerindeki aynı harfe en çok benzeyen örnek sayısının 9 olduğu saptanmıştır. Bu örneklerin frekansı 0.018 'dir.

5. Veri tabanında "y" harfinin 11 adet grup oluşturacak şekilde ayrı formu mevcuttur.

6. İnceleme konusu yazıdaki " $y$ " harfi ile mukayesedeki " $y$ " harfi veri tabanında 134 kişide görülmektedir ve bu "y" harfi formları kendi arasında ikinci kez ayrıma tabi tutulduğunda, inceleme konusu ve karşılaştırma cümlelerindeki aynı harfe en çok benzeyen örnek sayısının 8 olduğu saptanmıştır. Bu örneklerin frekansı 0.016 'dir.

7. Veri tabanında " $t$ " harfinin adet grup oluşturacak şekilde ayrı formu mevcuttur.

8. İnceleme konusu yazıdaki " $\mathrm{t}$ " harfi ile mukayesedeki " $t$ " harfi veri tabanında 47 kişide görülmektedir ve bu "t" harfi formları kendi arasında ikinci kez ayrıma tabi tutulduğunda, inceleme konusu ve karşılaştırma cümlelerindeki aynı harfe en çok benzeyen örnek sayısının 16 olduğu saptanmıştır. Bu örneklerin frekansı 0.032 'dir.

$\mathrm{P}(\mathrm{E} \mid \mathrm{Hd})=(0.058) \mathrm{x}(0.032) \mathrm{x}(0.018) \mathrm{x}(0.016)=5.3453 \times 10^{-7}$

$$
\mathrm{LR}=1 / 5.3453 \times 10^{-7}=1,870,809.387
$$

\subsection{Kurgusal Olgu}

Veri tabanında yer alan kişilerden birine, tehdit amacı ile yazısını değiştirmesini isteyerek aşağıdaki inceleme konusu cümle yazdırılmıştır.

\section{HLAN GAVAT AYAETNT DENX AL}

Aynı kişiye mukayesede kullanılmak üzere inceleme konusu cümlenin aynısı olan aşağıdaki cümleler yazdırilmıştır. 


\section{uLAN gavat aYAĞGNI DENK al} ULAN GAVAT AYAG̈INI DENK AL

Yukarıdaki inceleme konusu yazı ile karşılaştırmada kullanılacak olan yazılar incelendiğinde " $G$ " ve "A" karakterlerinde önemli derecede uygunluk ve benzerlikler mevcut olduğunu belirtilmiştir.

1. Veri tabanında "G" harfinin 19 adet grup oluşturacak şekilde ayrı formu mevcuttur.

2. İnceleme konusu yazıdaki "G" harfi ile mukayesedeki "G" harfi veri tabanında 187 kişide görülmektedir ve bu "G" harfi formları kendi arasında ikinci kez ayrıma tabi tutulduğunda, inceleme konusu ve karşılaştırma cümlelerindeki aynı harfe en çok benzeyen örnek sayısının 50 olduğu saptanmıştır. Bu örneklerin frekansı 0.1 'dir.

3. Veri tabanında "A" harfinin 18 adet grup oluşturacak şekilde ayrı formu mevcuttur.

4. İnceleme konusu yazıdaki "A" harfi ile mukayesedeki "A" harfi veri tabanında 24 kişide görülmektedir ve bu "A" harfi formları kendi arasında ikinci kez ayrıma tabi tutulduğunda, inceleme konusu ve karşılaştırma cümlelerindeki aynı harfe en çok benzeyen örnek sayısının 14 olduğu saptanmıştır. Bu örneklerin frekansı 0.028 'dir.

$$
\begin{gathered}
\mathrm{P}(\mathrm{E} \mid \mathrm{Hd})=(0.028) \times(0.1)=2.8 \times 10^{-3} \\
\mathrm{LR}=1 / 2.8 \times 10^{-3}=357.1429
\end{gathered}
$$

\subsection{Kurgusal Olgu}

Veri tabanında yer alan kişilerden birine, tehdit amacı ile yazısını değiştirmesini isteyerek aşağıdaki inceleme konusu cümle yazdırılmıştır.

\section{Ahlaksiz ve yalancisin. Serefsiz herif}

Aynı kişiye mukayesede kullanılmak üzere inceleme konusu cümlenin aynısı olan aşağıdaki cümleler yazdırilmıştır.

$$
\begin{aligned}
& \text { Ahlaksiz ve yalanasin. Seregsiz herif } \\
& \text { Ahlaksiz ve yalaasin. Seregsiz heig }
\end{aligned}
$$

Yukarıdaki inceleme konusu yazı ile karşılaştırmada kullanılacak olan yazılar incelendiğinde "A"harfi ve "ve" bağlacında önemli derecede uygunluk ve benzerlikler mevcut olduğunu belirtilmiştir.
1. Veri tabanında "A" harfinin 18 adet grup oluşturacak şekilde ayrı formu mevcuttur.

2. İnceleme konusu yazıdaki " $A$ " harfi ile mukayesedeki "A" harfi veri tabanında 189 kişide görülmektedir ve bu "A" harfi formları kendi arasında ikinci kez ayrıma tabi tutulduğunda, inceleme konusu ve karşılaştırma cümlelerindeki aynı harfe en çok benzeyen örnek sayısının 53 olduğu saptanmıştır. Bu örneklerin frekansı 0.106'dir.

3. Veri tabanında "ve" bağlacının 14 adet grup oluşturacak şekilde ayrı formu mevcuttur.

4. İnceleme konusu yazıdaki "ve" bağlacı ile mukayesedeki "ve" bağlacı veri tabanında 103 kişide görülmektedir ve bu "ve" bağlacı formları kendi arasında ikinci kez ayrıma tabi tutulduğunda, inceleme konusu ve karş1laştırma cümlelerindeki aynı harfe en çok benzeyen örnek sayısının 48 olduğu saptanmıştır. Bu örneklerin frekans1 0.096'dır.

$$
\mathrm{P}(\mathrm{E} \mid \mathrm{Hd})=(0.106) \mathrm{x}(0.096)=0.01018
$$

$$
\mathrm{LR}=1 / 0.01018=99.8203
$$

\subsection{Kurgusal Olgu}

Veri tabanında yer alan kişilerden birine, tehdit amacı ile yazısını değiştirmesini isteyerek aşağıdaki inceleme konusu senet yazdırılmıştır.

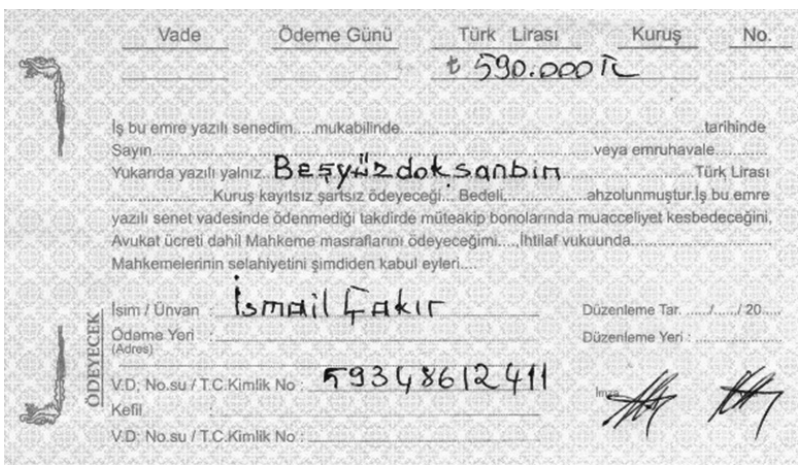

Aynı kişiye mukayesede kullanılmak üzere inceleme konusu cümlenin aynısı olan aşağıdaki cümleler yazdırılmıştır.

$$
\begin{aligned}
& \text { ìmail Caker } 590.000 \text { Tu. } \\
& 59348612411 \text { Besyor coksan bin }
\end{aligned}
$$

Yukarıdaki inceleme konusu yazı ile karşılaştırmada kullanılacak olan yazılar incelendiğinde " 5 " "9" ve " 0 " karakterlerinde önemli derecede uygunluk ve benzerlikler mevcut olduğunu belirtilmiştir.

1. Veri tabanında " 5 " rakamının 7 adet grup oluşturacak şekilde ayrı formu mevcuttur. 
2. İnceleme konusu yazıdaki " 5 " rakamı ile mukayesedeki "5" rakamı veri tabanında 65 kişide görülmektedir ve bu " 5 " rakamı formları kendi arasında ikinci kez ayrıma tabi tutulduğunda, inceleme konusu ve karş1laştırma cümlelerindeki aynı rakama en çok benzeyen örnek sayısının 20 olduğu saptanmıştır. Bu örneklerin frekans1 0.04'tür.

3. Veri tabanında "9" harfinin 14 adet grup oluşturacak şekilde ayrı formu mevcuttur.

4. İnceleme konusu yazıdaki “9” rakamı ile mukayesedeki "9" rakamı veri tabanında 28 kişide görülmektedir ve bu "9" harfi formları kendi arasında ikinci kez ayrıma tabi tutulduğunda, inceleme konusu ve karşılaştırma cümlelerindeki aynı harfe en çok benzeyen örnek sayısının 13 olduğu saptanmıştır. Bu örneklerin frekansı 0.026'dır.

5. Veri tabanında "0" rakamının 8 adet grup oluşturacak şekilde ayrı formu mevcuttur.

6. İnceleme konusu yazıdaki " 0 " rakamı ile mukayesedeki "0" rakamı veri tabanında 72 kişide görülmektedir ve bu "0" rakamı formları kendi arasında ikinci kez ayrıma tabi tutulduğunda, inceleme konusu ve karş1laştırma cümlelerindeki aynı harfe en çok benzeyen örnek sayısının 13 olduğu saptanmıştır. Bu örneklerin frekans1 0.026' tür.

$$
\begin{gathered}
\mathrm{P}(\mathrm{E} \mid \mathrm{H})=(0.04) \times(0.026) \times(0.026)=2.704 \times 10^{-5} \\
\mathrm{LR}=1 / 2.704 \times 10^{-5}=36,982.2485
\end{gathered}
$$

\subsection{Kurgusal Olgu}

Veri tabanında yer alan kişilerden birine, tehdit amacı ile yazısını değiştirmesini isteyerek aşağıdaki inceleme konusu cümle yazdırılmıştır.

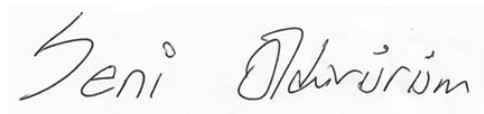

Aynı kişiye mukayesede kullanılmak üzere inceleme konusu cümlenin aynısı olan aşağıdaki cümleler yazdırılmıştır.

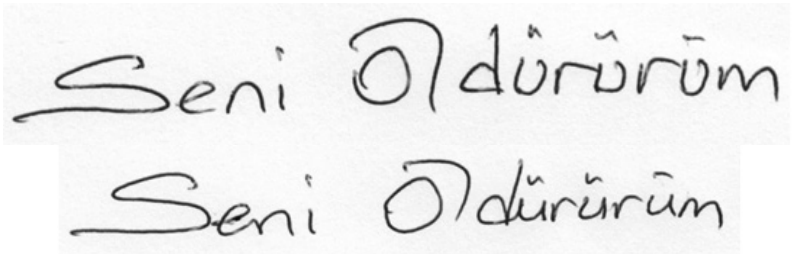

Yukarıdaki inceleme konusu yazı ile karşılaştırmada kullanılacak olan yazılar incelendiğinde “Ö” karakterinde önemli derecede uygunluk ve benzerlikler mevcut olduğunu belirtilmiştir.
Uzmanların ortak olarak önemli derecede benzerlik saptadığı “Ö” harfi veri tabanında araştırılmış ve aşağıdaki sonuçlar elde edilmiştir.

1. Veri tabanında "Ö" harfinin 24 adet grup oluşturacak şekilde ayrı formu mevcuttur.

2. İnceleme konusu yazıdaki "Ö" harfi ile mukayesedeki "Ö" harfi veri tabanında 3 kişide görülmektedir ve frekansı 0.006'dır.

$$
\begin{gathered}
\mathrm{P}(\mathrm{E} \mid \mathrm{H})=0.006 \\
\mathrm{LR}=1 / 0.006=166.6667
\end{gathered}
$$

\subsection{Kurgusal Olgu}

Veri tabanında yer alan kişilerden birine, tehdit amacı ile yazısını değiştirmesini isteyerek aşağıdaki inceleme konusu cümle yazdırılmıştır.

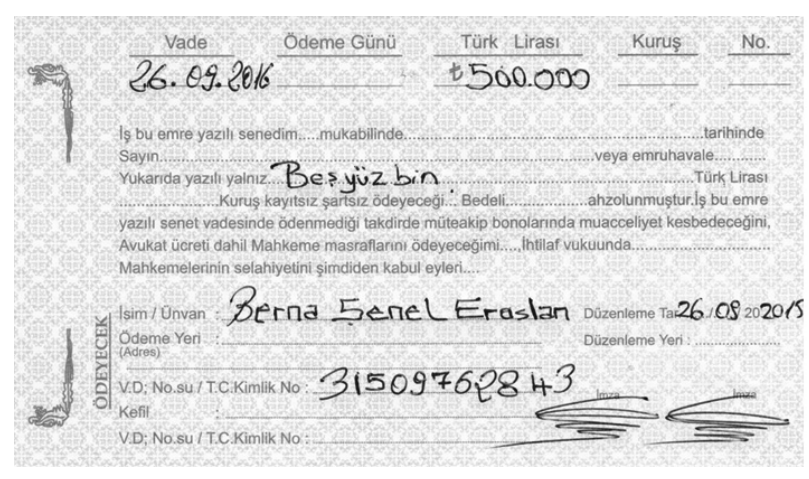

Aynı kişiye mukayesede kullanılmak üzere inceleme konusu cümlenin aynısı olan aşağıdaki cümle yazdırılmıştır.

$$
\begin{array}{cc}
\text { Berna Sencl Eraslan } \\
\begin{array}{cc}
26.09 .2016 & 31509762843 \\
26.09 .2016 & 500.000 \\
& \text { Besyübin }
\end{array}
\end{array}
$$

Yukarıdaki inceleme konusu yazı ile karşılaştırmada kullanılacak olan yazılar incelendiğinde ancak "B" "0" ve "9" karakterlerinde önemli derecede uygunluk ve benzerlikler mevcut olduğunu belirtilmiştir. "9" karakteri iki farklı yapılış göstermektedir.

1. Veri tabanında "B" harfinin 15 adet grup oluşturacak şekilde ayrı formu mevcuttur.

2. İnceleme konusu yazıdaki "B" harfi ile mukayesedeki "B" harfi veri tabanında 273 kişide görülmektedir ve bu "B" harfi formları kendi arasında ikinci kez ayrıma tabi tutulduğunda, inceleme konusu ve karşılaştırma cümlelerindeki aynı harfe en çok benzeyen örnek sayısının 9 olduğu saptanmıştır. Bu örneklerin frekansı 0.018 'dir. 
3. Veri tabanında "0" rakamının 8 adet grup oluşturacak şekilde ayrı formu mevcuttur.

4. İnceleme konusu yazıdaki "0" rakamı ile mukayesedeki "0" rakamı veri tabanında 188 kişide görülmektedir ve bu "0" rakamı formları kendi arasında ikinci kez ayrıma tabi tutulduğunda, inceleme konusu ve karş1laştırma cümlelerindeki aynı harfe en çok benzeyen örnek sayısının 18 olduğu saptanmıştır. Bu örneklerin frekans1 0.036'dir.

5. Veri tabanında "9" rakamının 14 adet grup oluşturacak şekilde ayrı formu mevcuttur.

6. İnceleme konusu yazıdaki birinci formdaki " 9 " rakamı ile mukayesede aynı formdaki "9" rakamı veri tabanında 13 kişide görülmektedir. Bu "9" rakamı formları kendi arasında ikinci kez ayrıma tabi tutulduğunda, inceleme konusu ve karşılaştırma cümlelerindeki aynı harfe en çok benzeyen örnek sayısının 4 olduğu saptanmıştır. Bu örneklerin frekansı 0.008'dir. İnceleme konusu yazıdaki ikinci formdaki "9" rakamı ile mukayesede ayn 1 formdaki "9" rakamı veri tabanında 36 kişide görülmektedir. Bu "9” rakamı formları kendi arasında ikinci kez ayrıma tabi tutulduğunda, inceleme konusu ve karşıllaştırma cümlelerindeki aynı harfe en çok benzeyen örnek sayısının 10 olduğu saptanmıştır. $\mathrm{Bu}$ örneklerin frekansı 0.02'dir.

$\mathrm{P}(\mathrm{E} \mid \mathrm{Hd})=(0.018) \mathrm{x}(0.036) \times(0.008) \times(0.02)=1.0368 \times 10^{-7}$

$$
\mathrm{LR}=1 / 1.0368 \times 10^{-7}=9,645,061.728
$$

\subsection{Kurgusal Olgu}

Veri tabanında yer alan kişilerden birine, tehdit amacı ile yazısını değiştirmesini isteyerek aşağıdaki inceleme konusu cümle yazdırılmıştır.

$$
\text { Allah helanc vehsin serin! }
$$

Aynı kişiye mukayesede kullanılmak üzere inceleme konusu cümlenin aynısı olan aşağıdaki cümleler yazdırılmıştır.

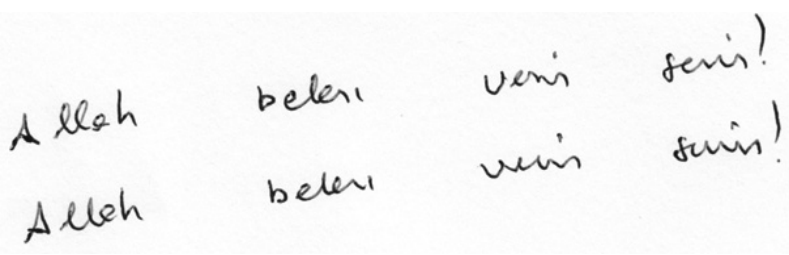

Yukarıdaki inceleme konusu yazı ile karşılaştırmada kullanılacak olan yazılar incelendiğinde ancak " $\mathrm{A}$ " ve "b" karakterlerinde önemli derecede uygunluk ve benzerlikler mevcut olduğunu belirtilmiştir.
1. Veri tabanında "A" harfinin 18 adet grup oluşturacak şekilde ayrı formu mevcuttur.

2. İnceleme konusu yazıdaki "A" harfi ile mukayesedeki "A" harfi veri tabanında 79 kişide görülmektedir ve bu "B" harfi formları kendi arasında ikinci kez ayrıma tabi tutulduğunda, inceleme konusu ve karşılaştırma cümlelerindeki aynı harfe en çok benzeyen örnek sayısının 39 olduğu saptanmıştır. Bu örneklerin frekansı 0.078 'dir.

3. Veri tabanında "b" harfinin 9 adet grup oluşturacak şekilde ayrı formu mevcuttur.

4. İnceleme konusu yazıdaki "b" harfi ile mukayesedeki "b" harfi veri tabanında 395 kişide görülmektedir ve bu "b" harfi formları kendi arasında ikinci kez ayrıma tabi tutulduğunda, inceleme konusu ve karşılaştırma cümlelerindeki aynı harfe en çok benzeyen örnek sayısının 39 olduğu saptanmıştır. Bu örneklerin frekansı 0.078'dir.

$$
\begin{aligned}
\mathrm{P}(\mathrm{E} \mid \mathrm{Hd}) & =(0.024) \times(0.03)=7.2 \times 10^{-4} \\
\mathrm{LR} & =1 / 7.2 \times 10^{-4}=1,388.8889
\end{aligned}
$$

\subsection{Kurgusal Olgu}

Veri tabanında yer alan kişilerden birine, tehdit amacı ile yazısını değiştirmesini isteyerek aşağıdaki inceleme konusu cümle yazdırılmıştır.

\section{Qlümür barim alimder olacak}

Aynı kişiye mukayesede kullanılmak üzere inceleme konusu cümlenin aynısı olan aşağıdaki cümleler yazdırılmıştır.

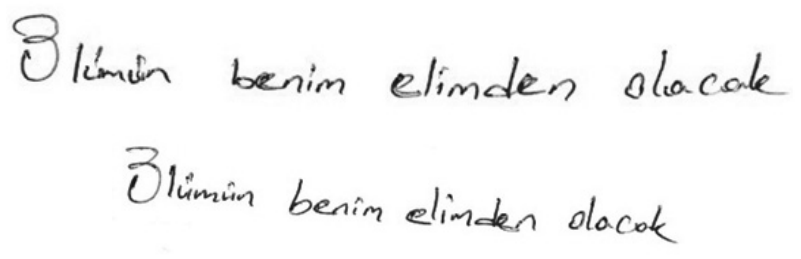

Yukarıdaki inceleme konusu yazı ile karşılaştırmada kullanılacak olan yazılar incelendiğinde ancak "Ö" "b" ve "d" karakterlerinde önemli derecede uygunluk ve benzerlikler mevcut olduğunu belirtilmiştir.

1. Veri tabanında "Ö" harfinin 24 adet grup oluşturacak şekilde ayrı formu mevcuttur.

2. İnceleme konusu yazıdaki “Ö” harfi ile mukayesedeki "Ö" harfi veri tabanında 1 kişide görülmektedir ve frekans1 0.002 'dir.

3. Veri tabanında "b" harfinin 9 adet grup oluşturacak şekilde ayrı formu mevcuttur. 
4. İnceleme konusu yazıdaki "b" harfi ile mukayesedeki "b" harfi veri tabanında 321 kişide görülmektedir ve bu "b" harfi formları kendi arasında ikinci kez ayrıma tabi tutulduğunda, inceleme konusu ve karşılaştırma cümlelerindeki aynı harfe en çok benzeyen örnek sayısının 210 olduğu saptanmıştır. Bu örneklerin frekansı 0.42 'dir.

5. Veri tabanında "d" harfinin 11 adet grup oluşturacak şekilde ayrı formu mevcuttur.

6. İnceleme konusu yazıdaki "d" harfi ile mukayesedeki "d" harfi veri tabanında 395 kişide görülmektedir ve bu "d" harfi formları kendi arasında ikinci kez ayrıma tabi tutulduğunda, inceleme konusu ve karşılaştırma cümlelerindeki aynı harfe en çok benzeyen örnek sayısının 50 olduğu saptanmıştır. Bu örneklerin frekansı 0.1 'dir.

$$
\begin{gathered}
\mathrm{P}(\mathrm{E} \mid \mathrm{Hd})=(0.42) \times(0.1) \times(0.002)=8.4 \times 10-5 \\
\mathrm{LR}=1 / 8.4 \times 10^{-5}=11,904.7619
\end{gathered}
$$

\section{Tartışma}

El yazıs1 incelemelerinde aidiyet belirlenirken veya birden fazla yazının aynı kişiye mi yoksa farklı kişiye mi ait olduğu saptanırken incelemeyi yapan uzmanlar tarafindan yıllar süren bir tecrübe birikimi ile geliştirilmiş yeteneklerle çok sayıda tanı kriteri kullanılarak bir kanaate varılmaktadır. İnceleme sonucu elde edilecek sonuçlar ve varılacak kanaatler gerek işin niteliği gerek incelemede kullanılan ekipmanların yeterliliği gerekse incelemeyi yapan uzmanın özen, dikkat ve tecrübesinin varılacak sonuçların sağlığını belirleyici olacağı açıtır. Ancak her üç bakımdan en iyi şartlarda bile sonuç kesin olmayacak ve az da olsa bir yanılgı payı bulunacaktır.

Elde edilen sonuçlardaki yanılgı payı iki şekilde olabilir. Ya yanlış bir aidiyet belirlenebilecek ve bir kişiye ait olmayan bir yazının ona ait olduğu söylenebilecek veya incelenen yazı aslında bir kişiye ait iken ona ait olmadığı saptanabilecektir. Yazı veya yazıları yazan farklı kişilerin sayısının yanlış belirlenmesi veya hiç belirleme yapılamaması yazı incelemelerinde karşılaşılan olumsuz sonuçlar olacaktır.

Bir yazı incelemesinde incelenen yazının asıl olması, nispeten uzun olması ve yazan kişinin değiştirme gayreti içerisinde olmaması durumunda karşılaştırma belgelerinin yeterli incelemeyi yapan uzmanın tecrübeli olmas1 halinde hata payı çok düşük olabilir. Ancak tersi bir durumda hata payı yükselecektir. Hata payını en aza yaklaştıran etkenlerden biri incelemenin yeterli zaman ayrılarak yeterli dikkat sarf edilerek ve mümkün olduğu kadar fazla tanı kriteri kullanılarak yapılmasıdır. Tanı kriterleri arasında uzmanlar tarafindan en çok ve sık kullanılanlar; ya- zının genel karakteri, kelime ve harf aralıkları, harflerin yapılış biçimleri, hacimleri, kısımlarının oranları, eğimleri, bağlantı ve noktalama özellikleri, normalden sapma alışkanlıkları, başlangıç noktaları ve sonlandırılışları, hız, işleklik ve baskı dereceleridir. Bu tanı kriterleri değerlendirilirken aidiyet belirlenmesinde kişiye ait bireysel karakteristiklerin hem inceleme konusu olan yazıda hem de kişiye ait olduğu bilinen ve karşılaştırmada kullanılan yazılarda aynı anda saptanması büyük önem taşıyacaktır.

Tanıda kullanılan karakteristiklerin çok az sayıda sadece o kişiye ait olacağı ancak çok daha fazla sayıda sadece o kişiye ait olmayıp "normalden sapma" şeklinde görüleceği söylenebilir. Dolayısıyla bireysel karakteristik olarak kabul edilen ve özellikle aidiyetin pozitif yönde belirlendiği incelemelerde belirlenen karakteristiklerin toplumda hangi sıklıkta görüldüğü, varılan sonuçların güvenilirliği bakımından büyük ölçüde önem taşıyacaktır. Pozitif aidiyet belirlendiğinde saptanan ve karakteristik olduğu kabul edilen bulgunun toplumda görülme sıklığ azaldıkça tespit edilen pozitif aidiyetin güvenilirliği matematiksel olarak artacaktır. Yine toplumda görülme sıklığ sıyla bireysel karakteristik olarak kabul edilen bulgunun varlığı ise orantılı olarak matematiksel olasılığı artıracaktır. İşte bu sebeplerle son yıllarda yazı incelemelerinde belli bir topluma ait veri tabanları oluşturularak bir yazı incelemesinde sonuca götüren tanı kriterlerinin o toplumda ne sıklıkta görüldüğünün belirlenmesi ve bu kriterlerin matematiksel olarak tanıyı ne kadar desteklediğinin bulunması son derece yaygınlaşmıştır. Veri tabanı oluşturulması konusunda en eski ve tanınan çalışmalardan biri “Sargur Srihari’nin” 1500 yüksekokul öğrencisinde yapmış olduğu çalışmadır (42).

Ülkemizde yazı karşılaştırmalarında kullanılmak amacı ile oluşturulmuş herhangi bir veri tabanı çalışması mevcut değildir. Yapılan literatür araştırmasında bununla ilgili bir yayına rastlanmamıştır. Farklı toplumların yazı yazma alışkanlıklarının ve öğretilerinin farklı olduğu ve farklı dil ailelerine ait yazıların farklılık gösterdiği dikkate alındığında her toplum için yeterince geniş veri tabanlarının oluşturulması zorunluluğu ortaya çıkmaktadır. Nitekim son yıllarda farklı ülkelerde yapılan veri tabanı çalışmaları ile ilgili çok sayıda literatür mevcuttur (3941,44,45). Bu konudaki en yeni ve en kapsamlı çalışmalardan biri Amerika'da yürütülen "Measuring the Frequency Occurrence of Handwriting and Hand-Printing Characteristics" adlı projedir (38).

$\mathrm{Bu}$ çalışmada yazı örnekleri alınan kişiler üniversite veya yüksekokul öğrencileri ile mezunları, lisansüstü eğitim öğrencileri ve mezunlarıdır. Böyle bir veri tabanı sadece aynı düzeyde eğitim görmüş kişilere ait yazıların 
incelenmesinde kullanılabilir. Daha düşük düzeyde eğitime sahip kişilere ait yazıların karşılaştııılmasında daha sağlıklı sonuçlara ulaşılabilmesi için aynı düzey eğitime sahip kişilere ait veri tabanlarının oluşturulması gerektiği bir gerçektir. Bu şekildeki her eğitim seviyesindeki kişileri içeren bir veri tabanı genelde herkes için kullanılabileceği gibi sadece yazıları üzerinde inceleme yapılan kişinin eğitim grubundan oluşan veri tabanları da kullanılabilir.

$\mathrm{Bu}$ çalışmada yazı karşılaştırması yapılırken tanıya götüren önemli etkenlerden biri olan ve incelemeyi yapan uzmanlar tarafindan saptanan tek tek harflerdeki yapılış biçimi ve form benzerliğinin veri tabanında araştırma yapıldığında matematiksel olarak ne derece değer taşıdığı başka bir anlatımla toplumda görülme sıklığının ne olduğu araştırılmıştır.

Bu noktada 500 kişiden oluşan bir veri tabanının ülkedeki aynı düzeyde eğitime sahip toplum için güvenilir bir sayı olup olmadığı tartışılabilir. Günümüze kadar başka ülkelerde oluşturulan veri tabanlarının sayısı ve kullanılan ülkelerin nüfusu kıyaslandığında bu sayının yeterli olduğu söylenebilir.

Burada asıl sorun tarafimızca frekansların tespitinde kullanılan benzetmelerin kişiden kişiye değişebileceği ve frekansların farklı değerler alabileceğidir. Ancak bu sakıncanın, veri tabanı kullanımının sağlayacağı faydaları önemli ölçüde yok etmeyeceği kanaatindeyiz.

Uzman, incelemede elde ettiği özellikle normalden sapmaları değerlendirirken, söz konusu normalden sapmayı yani alfabe öğretisinden farklı formu, daha önce gördüğü ve hafızasında kalan örneklere göre "az rastlanır" olarak kabul edip aidiyet açısından çok önemli olarak görebilir. Ancak önemli olan bu sapmanın veya bu farklı formun toplumda gerçekten ne sıklıkla görüldüğünün say1sal olarak tespit edilmesidir. Bu sayısal tespitin yap1labilmesi için ise veri tabanı kullanımı şarttır ve başka alternatifi yoktur. Veri tabanı iki şekilde elde edilebilir. Ya bu çalışmada olduğu gibi aydınlatılmış onamı alınan katılımcılardan elde edilecek örnekler kullanılacak veya uzmanların daha önce üzerinde inceleme yaptıkları örnekler kullanılacaktır. Ancak ikinci durumda her kişiden çok az örnek bulunması gibi sakıncalı bir durum söz konusu olacaktır. Veri tabanı üzerinde yapılacak araştırma sonucu elde edilen sonuçların hazırlanacak olan rapora aksettirilmesi halinde bu tür veri tabanı kullanımı ile ilgili etik sorunlar da ortaya çıkabilir.

İkinci sorun; elde edilen frekans değerlerinin olasılık olarak nasıl değerlendirileceğidir. Bu değerlendirmenin genel olarak yapılabileceği gibi her bir işin kendi özelliklerine göre uzmanın kendisi tarafından yapılması gerektiği kanaatindeyiz. Büyük bir iş yerindeki yöneticiye gönderilen hakaret mektubundaki yazıların çalışan 200 kişiden kime ait olduğunun tespiti ile bir sahte çekin üzerindeki yazıların tek bir sanığa ait olup olmadığının tespitinde güvenilirlik sınırı aynı olmamalıdır. Uzman, birinci durumda frekansı düşük birkaç benzerliği aidiyet için güvenilir görmezken, ikinci durumda frekansı düşük tek bir benzerliği bile aidiyet belirlemede yüksek güvenilirlik olarak kabul edebilir. Elbette ki raporunu düzenlerken bu düşüncesini açıkça belirtmesi, raporu değerlendirecek hukukçu için denetime açık ve yol gösterici bir bilimsel tespit oluşturacaktır.

Literatürde olabilirlik oranlarının nasıl değerlendirileceği ile ilgili ölçekler mevcuttur. Bu ölçeklerden biri çalışmadaki bulguların değerlendirilmesinde kullanılmıştır (Tablo 5).

Tablo 5: Olabilirlik oranlarının yorumlanması için ölçek (20).

\begin{tabular}{|c|c|c|}
\hline $\begin{array}{l}\text { Sayısal } \\
\text { Ölçek }\end{array}$ & Sözel Ölçek & $\begin{array}{c}\text { Olabilirlik Oranı } \\
\text { Aralığı } \\
\end{array}$ \\
\hline+4 & $\begin{array}{c}\text { İnceleme sonuçları } \\
\text { son derece kuvvetli } \\
\text { şekilde iddia makamı } \\
\text { hipotezini destekliyor. }\end{array}$ & $\mathrm{LR} \geq 1,000,000$ \\
\hline+3 & $\begin{array}{c}\text { İnceleme sonuçları } \\
\text { kuvvetli şekilde iddia } \\
\text { makamı hipotezini } \\
\text { destekliyor. } \\
\end{array}$ & $6,000 \leq \mathrm{LR}<1,000,000$ \\
\hline+2 & $\begin{array}{c}\text { İnceleme sonuçları } \\
\text { iddia makamı } \\
\text { hipotezini destekliyor. }\end{array}$ & $100 \leq \mathrm{LR}<6,000$ \\
\hline+1 & $\begin{array}{l}\text { İnceleme sonuçları } \\
\text { kısıtlı bir şekilde iddia } \\
\text { makamı hipotezini } \\
\text { destekliyor. }\end{array}$ & $6 \leq \mathrm{LR}<100$ \\
\hline 0 & Tespit yok. & $1 / 6 \leq \mathrm{LR}<6$ \\
\hline-1 & $\begin{array}{l}\text { İnceleme sonuçları } \\
\text { kısıtlı bir şekilde } \\
\text { iddia hipotezini } \\
\text { desteklemiyor. }\end{array}$ & $1 / 6 \geq L R>1 / 100$ \\
\hline-2 & $\begin{array}{c}\text { İnceleme sonuçları } \\
\text { iddia hipotezini } \\
\text { desteklemiyor. } \\
\end{array}$ & $1 / 100 \geq \mathrm{LR}>1 / 6,000$ \\
\hline-3 & $\begin{array}{l}\text { İnceleme sonuçları } \\
\text { kuvvetli bir şekilde } \\
\text { iddia hipotezini } \\
\text { desteklemiyor. } \\
\end{array}$ & $\begin{array}{c}1 / 6,000 \geq \mathrm{LR}> \\
1 / 1,000,000\end{array}$ \\
\hline-4 & $\begin{array}{l}\text { İnceleme sonuçları } \\
\text { son derece } \\
\text { kuvvetli bir şekilde } \\
\text { iddia hipotezini } \\
\text { desteklemiyor. }\end{array}$ & $\mathrm{LR} \leq 1,000,000$ \\
\hline
\end{tabular}


Bulgular kısmındaki birinci olguda olabilirlik oranı 228.9377 hesaplanmış olup bu değer yazıların aynı kişiye ait olduğunu desteklemektedir.

İkinci olguda olabilirlik oranı 223,214,285.7 hesaplanmış olup bu değer yazıların aynı kişiye ait olduğunu çok kuvvetle desteklemektedir.

Üçüncü olguda olabilirlik oranı 1,870,809.387 hesaplanmış olup bu değer yazıların aynı kişiye ait olduğunu çok kuvvetle desteklemektedir.

Dördüncü olguda olabilirlik oranı 357.1429 hesaplanmış olup bu değer yazıların aynı kişiye ait olduğunu desteklemektedir.

Beşinci olguda olabilirlik oranı 99.8203 hesaplanmış olup bu değer yazıların aynı kişiye ait olduğunu zayıf olarak desteklemektedir.

Kanaatimizce yalnızca bu kriterlere dayanılarak inceleme konusu el yazısının kişiye ait olduğunu söylemek oldukça güçtür.

Altınc1 olguda olabilirlik oran $36,982.2485$ hesaplanmış olup bu değer yazıların aynı kişiye ait olduğunu kuvvetle desteklemektedir.

Yedinci olguda olabilirlik oranı 166.6667 hesaplanmış olup bu değer yazıların aynı kişiye ait olduğunu desteklemektedir.

Sekizinci olguda olabilirlik oranı 9,645,061.728 hesaplanmış olup bu değer yazıların aynı kişiye ait olduğunu çok kuvvetle desteklemektedir.

Dokuzuncu olguda olabilirlik oran 1,388.8889 hesaplanmış olup bu değer yazıların aynı kişiye ait olduğunu desteklemektedir.

Onuncu olguda olabilirlik oranı 11,904.7619 hesaplanmış olup bu değer yazıların aynı kişiye ait olduğunu kuvvetle desteklemektedir.

Elde edilen değerlerden anlaşıldığına göre özellikle kısa yazılarda çok karakteristik olsa ve toplumda çok az rastlansa bile tek bir harfin benzetilmesi ile aidiyetin belirlenmesi matematiksel istatistik açısından kuvvetli olarak desteklenmemektedir. Bu tür durumlarda ya kesin bir sonuca varmamak veya kuvvetlendirici başka unsurları da kullanmak gerekecektir.

Bu çalışmada veri tabanı oluşturmanın yazı incelemelerine katacağı artı değer tartışılırken sadece bazı harflerin formasyonu göz önüne alınmıştır. Bunun dışında yazı incelemelerinde kullanılan tüm tanı kriterleri açısından veri tabanı kullanılabilir ve saptanan her bulgunun fre- kansı bulunabilir. Grafometrik ölçüm değerlerinin ortalaması veya karşılaşılma sıklığı saptanabilir. Kelime ve harf aralıkları, harflerin ebadı, kısımlarının oranları bakımından kıyaslama yapılabilir. Hız, işleklik ve baskı derecesi değişiklikleri araştırılabilir. Bunların da yapılması halinde veri tabanı kullanımının pratikte yapılan bilirkişilik uygulamalarına çok büyük katkılar sağlayacağ 1 kanaatindeyiz.

\section{Sonuç}

Yapılan çalışmadan incelenen literatür ışığında ve elde edilen bulgular doğrultusunda aşağıdaki sonuçlar elde edilmiştir.

1. Son yıllarda yazı incelemelerinde uzmanların tespit ettiği aidiyet ile ilgili bulgular önceden hazırlanmış veri tabanları ile karşılaştırılarak aidiyetin saptanmasında kullanılan karakteristiklerin toplumda ne oranda görüldüğü dolayısıyla olasılık oranının ne olduğu şeklinde sayısal tespitler yapılmaktadır.

2. Ülkemizde henüz belirtilen amaç doğrultusunda geliştirilmiş bir veri tabanı mevcut değildir.

3. Yapılan çalışmada örnek olgular üzerinde gerçekleştirilen karşılaştırmaların, karakteristiklerin güvenilirliğinin sayısal ifadesi bakımından çok büyük kolaylık sağladığı ve somut verilere ulaşılabildiği saptanmıştır.

4. Veri tabanı üzerinde sadece bu tezde yapılan harflere ait formal özellikler değil yazı karşılaştırmalarında kullanılan tanısal unsurların tümü araştırılabilir ve karşılaştırılabilir.

5. Bu çalışma sadece toplumun eğitim bakımından belli bir kesimini temsil etmektedir. Toplumun tüm kesimini temsil eden çalışmalara ihtiyaç vardır.

6. Veri tabanı oluşturulurken standart bir uygulama yapılması gerekmektedir. Geniş katılımlı bu çalışmada kullanılan materyalin yazım şartlarının ve sürenin, kişinin pozisyonunun aynı olması önem taşımaktadır. Kutucuklara büyük ve küçük harfler ile rakamların tek tek yazdırılması kullanım amacına uygunluğu tam olarak sağlamamaktadır.

7. Veri tabanı, uzmanlar tarafindan yazı incelemesi ile ilgili bir rapor hazırlanmadan önce veya hazırlama aşamasında kullanılabileceği gibi hazırlanmış olan bir raporun pozitif veya negatif yönde değerlendirilmesinde de kullanılabilir. 


\section{Kaynaklar}

1. Aitken CGG, Taroni F. Statistics and the evalution of evidence for forensic scientists. 2. bask1, Chichester: John Wiley\& Sons Ltd, The Atrium, Southern Gate, Chichester, West Sussex PO19 8SQ, England, 2004.

2. Adam C. Essential mathematics and statistics for forensic science. 1.bask1, Chichester: John Wiley \& Sons, Ltd, The Atrium, Southern Gate, Chichester, West Sussex PO198SQ, England, 2010.

3. Lucy D. Introduction to Statistics for Forensic Scientists. 1. bask1, Chichester: John Wiley \& Sons, Ltd, The Atrium , Southern Gate, Chichester, West Sussex PO198SQ, England, 2005.

4. Taroni F, Marquis R, Schmittbuhl M, Biedermann A, Thie'ry A, Bozza S. The use of the likelihood ratio for evaluative and investigative purposes in comparative forensic handwriting examination, Forensic Sci Int, 2012;214:189-194

5. Tang Y, Srihari SN. Likelihood ratio estimation in forensic identification using similarity and rarity, Pattern Recognition, 2014;47:945-958

6. Morrison GF. Measuring the validity and reliability of forensic likelihood-ratio systems, Science \& Justice, 2011;51: 91-98

7. Srihari SN, Singer K. Role of automation in the examination of hand written items, Pattern Recognition, 2014;47:1083-1095

8. Biedermann A, Voisard R, Taroni F. Learning about Bayesian networks awardfor forensic interpretation: An example based on the problem of multiple propositions, Science \&Justice, 2012;52:191-198

9. Forster MR. Counterexamples to a likelihood theory of evidence, J Minds Machines, 2006;16:319-338

10. Srihari SN, Srinivasan H. Comparison of ROC and likelihood decision methods in automatic fingerprint verification, Int J Pattern Recognition Artificial Intelligence, 2008;22:535-553

11. Srihari SN, Huang C, Srinivasan, H. On the discriminability of the handwriting of twins, J Forensic Sci, 2008;53:430-446

12. Evett IW, Jackson G, Lambert JA, McCrossan S. The impact of the principles of evidence interpretation on the structure and content of statements, Science \& Justice, 2000;40:233-239

13. Xu Z, Srihari SN. Bayesian network structure learning and Inference Methods for Handwriting, Proceeding of 12th International Conference on Document Analysis and Recognition;2013 1320 - 1324: Washington, DC doi:10.1109/ ICDAR.2013.267

14. Marquis R, Taroni F, Bozza S, Schmittbuhl M. Quantitative characterization of morphological polymorphism of handwritten characters loops, Forensic Sci Int, 2006;164:211-220

15. Bozza S, Taroni F, Marquis R, Schmittbuhl M. Probabilistic evaluation of handwriting evidence: likelihood ratio for authorship, J Royal Statistical Society, 2008;57:329-341

16. Cardinetti B, Cammarota C, Negative conclusion cases: further proposal for likelihood ratio evaluation, Law, Probability and Risk Advance, 2007:1-16, doi:10.1093/lpr/mg1018

17. Srihari SN. Determining writership of historical manuscripts using computational methods, Automatic Pattern
Recognition and Historical Handwriting Analysis workshop presented at Erlengen, Germany, June 14-15, 2013

18. Srihari SN, Tomai CI, Zang B, Sangjik L. Individuality of Numerals. Proceedings of the Seventh International Conference on Document Analysis and Recognition (ICDAR 2013)

19. Srihari S, Huang C, Srinivasan H. Content-based information retrieval from handwritten documents, U.S. Department of Justice, National Institute of Justice Grant 2002-LTBX-K007

20. Nordgaard A, Ansell R, Drotz W, Jaeger L. Scale of conclusions fort he value of evidence, Law Probability and Risk, 2011;1-24 doi:10.1093/lpr/mgr020

21. Aitken CGG, Taroni F. A verbal scale for the interpretation of evidence, Science \& Justice, 38;(1998): 279-283

22. Cereda G. Impact of model choice on LR assessment in case of rare haplotype match (frequentist approach), 2015 arXiv: 1502.04083

23. Taroni F, Aitken C, Garbolino P, Biedermann A, Bayesian Networks and Probabilistic Inference in Forensic Science. Barnett V, editör, 2006, doi: 10.1002/0470091754

24. Biedermann A, Taroni F. Findings evaluation in forensic manuscript examination: Necessity of a logical approach. Kriminalistik, 2005; 59:369-370

25. Taroni F, Bozza S, Biedermann A, Aitken C. Dismissal of the illusion of uncertainty in the assessment of a likelihood ratio, Law Probability and Risk, 2016;15:1-16 doi: 10.1093/ lpr/mgv008

26. Godambe VP, Finetti Bd. Probability, Induction and Statistics. J Am Statistical Association, 1974: 69(346):578 doi: $10.2307 / 2285706$

27. Dørum G, Bleka Ø, Gill P, Egeland T. Exact computation of the distribution of likelihood ratios with forensic applications, Forensic Science International: Genetics, 2014;9(1):93-101 doi: 10.1016/j.fsigen.2013.11.008

28. Berger CEH, Buckleton J, Champod C, Jackson G. Evidence evaluation: A response to the court of appeal judgment in R. v. T. Science \& Justice, 2011,;51(2):43-9 •

29. Neumann C, Kaye D, Jackson G, Ranadive A. Presenting Quantitative and Qualitative Information on Forensic Science Evidence in the Courtroom. Chance, 2016; 29(1):3743

30. Biedermann A, Taroni F, Bozza S. Implementing statistical learning methods through Bayesian networks. Part 1: A guide to Bayesian parameter estimation using forensic science data. Forensic Sci Int, 2009;193(1-3):63-71 doi: 10.1016/j.forsciint.2009.09.007

31. Neumann C, Ranadive A, Kaye DH, Reyna V. Communicating the Results of Forensic Science Examinations. Final Technical Report for NIST Award 70NANB12H014, 2015 doi: 10.13140/RG.2.1.2078.8246

32. Taroni F, Biedermann A, Bozza S. Statistical hypothesis testing and common misinterpretations: Should we abandon p-value in forensic science applications? Forensic Sci Int, 2016; 259:32-36 · DOI: 10.1016/j.forsciint.2015.11.013 
33. Meuwly D. Forensic individualisation from biometric data, Science \& Justice, 2006;46:205-213

34. Evett IW, Weir SB, Interpreting DNA evidence:Statistical genetics for forensic scientists, Sinauer Associates, Sunderland, MA, 1998

35. Saini M, Kapoor AK. Conventional and computational features in document examination, J Forensic Sci \& Criminology, 2015;3:1-7

36. Desai B, Kalyan JL. Forensic examination of handwriting and sigantures, Int J Innovative Research\&Development, 2013;2:514-527. Doi: 10.15744/2348-9804.3.301

37. Hussain R, Raza A, Siddiqi I, Khursid K, Djeddi C. A compherensive survey of handwritten document benchmarks: structure, usage and evalution, J Image Video Processing, 2015;46:1-24. Doi:10.1186/s13640-015-0102-5

38. Johnson ME, Vastrick TW, Boulanger M, Schuetzner EM. Measuring the Frequency occurrence of handwriting and hand-printing characteristics, National Institute of Justice, Award Number 2010-DN-BX-K273.

39. Davis LJ , Saunders CP , Hepler A, Buscaglia J. Using subsampling to estimate the strength of handwriting fevidence via score-based likelihood ratios, Forensic Sci
Int,2012;216:146-157

40. Raymond M, Bozza S, Schmittbuhl M, Taroni F. Handwriting evidence evaluation based on the shape of characters: Application of multivariate likelihood ratios, J Forensic Sci, 2011;56:238-242

41. Hepler AB, Saunders CP, Davis LJ, Buscaglia J. Scorebased likelihood ratios for handwriting evidence, Forensic Sci Int,2012;219:129-140

42. Srihari SN. Statistical examination of handwriting characteristics using automated tools. NIJ Report 241743, 2013, Award Number: 2010-DN-BX-K037

43. Srihari SN. Computational methods for handwritten questioned document examination. NIJ Report 232745, 2010, Award Number:2004-IJ-CX-K050

44. Marquis R, Schmittbuhl M, Mazzella WD, Taroni F. Quantification of the shape of handwritten characters:a step to objective discrimination between writers based on the study of the capital character O, Forensic Sci Int, 2005;150:23-32

45. Akkurt M. Adli tıp kurumu fizik ihtisas dairesi adli belge inceleme şubesine gelen ve müzekkere ile iade edilen dosyaların incelenmesi [MSc tezi], Ulusal Tez Merkezi 308084, 2011. 